\title{
The effect of age upon the coagulation system
}

\author{
P. J. HAMILTON, MARY AllardyCE, D. OGSTON, AUDREY A. DAWSON, \\ AND A. S. DOUGLAS
}

From the Departments of Medicine and Pathology, University of Aberdeen

SYNOPSIS Factors V, VII, VIII, X, XI, and XII of the coagulation system, platelet count, and antithrombin III levels were assayed in 20 healthy volunteers aged 20-40 years and 61 elderly subjects aged 66-96 years whose skinfold thickness was also measured. Factors XI, XII, and antithrombin III levels tended to increase in women and decrease in men while factors X, VII, and V N tended to increase in both males and females with advancing years. No age or sex differences were $\vec{N}$ found in platelet counts or factor VIII levels. Factor VIII levels were inversely correlated with obesity in elderly males $(\mathrm{r}=-0.56, \mathrm{P}<0.005)$.

Advancing years and obesity have been associated clinically with an increased incidence of atheroma and thrombosis (Morrell and Dunnill, 1968; Vessey and Doll, 1969; Kakkar, Howe, Nicolaides, Renney, and Clarke, 1970). There are, however, few reports detailing age-related changes in the blood coagulation system. In this study a comparison has been made of the platelet count, coagulation factors XII, XI, VIII, $\mathrm{X}, \mathrm{V}$, and VII, antithrombin III levels, and skinfold thickness in an apparently healthy elderly group living in the community and in young healthy subjects.

\section{Materials and Methods}

\section{SUBJECTS}

The elderly group comprised 29 males and 32 females aged 66-96 years, chosen from the records of one group practice of general practitioners. No subject had a medical record of carcinoma, diabetes, venous or arterial thrombosis, hypertension, or symptomatic arteriosclerotic disease. All subjects were ambulant and in apparent good health at the time of study. They were bled in their own homes between $9.15 \mathrm{am}$ and $10.30 \mathrm{am}$. The young subjects were 10 male and 10 female healthy hospital personnel. None were receiving drugs or hormone preparations.

\section{BLOOD SAMPLING}

Blood was collected into a plastic syringe through 19 SWG needles after careful venepuncture of an antecubital vein using minimal venous stasis. It was

Received for publication 4 September 1974. kept at $4^{\circ} \mathrm{C}$ until separated and the plasma and serum were stored at $-70^{\circ} \mathrm{C}$ for up to six months.

\section{COAGULATION FACTOR ASSAYS}

These were performed on aliquots of freshly thawe $\$$ citrated platelet-poor plasma and levels expressed as percentage activity with respect to reference plasm obtained from a pool of fresh citrated blood from eight healthy male subjects aged $20-25$ years.

\section{Factors XII, XI, and VIII}

These assays were based upon the partial thromboplastin time using minor modifications of the methods detailed by Denson (1972). Commercial human deficient substrate plasmas (General Diagnostics, Morris Plains, New Jersey, USA) and platelet substitute (Diagnostic Reagents, Thame, Oxon, UK) were used.

\section{Factors $X, V$ and $V I I$}

Factor $\mathrm{X}$ was assayed by a Russell viper venom cephalin one-stage recalcification clotting time test using factor $\mathrm{X}$-deficient charcoal filtered ox plasma substrate (Diagnostic Reagents) and factors $\mathrm{V}$ and VII were measured by tests based on one-stage prothrombin time tests using the suitable substrate plasmas (General Diagnostics) and saline human brain extract (Denson, 1972).

\section{Antithrombin III}

Levels were assayed by quantitative single radial immunodiffusion of sera (Mancini, Carbonara, and Heremans, 1963) using standardized reference sera and antiserum obtained from Nyegaard \& Co. R/S. Oslo, Norway. 


\section{Platelet counts}

These were determined within two hours of venepuncture by the method of Oettle and Spriggs (1951).

\section{Skinfold thickness}

This was assessed by one observer over the right triceps using skin calipers (John Bull, British Indicators Ltd, St Albans, Herts, UK). Measurements in mm were converted to units as recommended by Edwards, Hammond, Healy, Tanner, and Whitehouse (1955).

\section{Results}

The sexes differed in the effects of increasing age upon some of the parameters measured in this study. In order to facilitate assessment of such changes male and female subjects were divided into three subgroups, aged 20-40 years, 66-75 years, and over 76 years. The findings are summarized in table $I$.

Factors XII, XI, and antithrombin III levels were significantly elevated in all females over 65 years when compared with the findings in their male counterparts $(\mathrm{r}=0.40, \mathrm{P}<0.005 ; \mathrm{r}=0.35, \mathrm{P}<$ 0.001 , and $\mathrm{r}=0.46, \mathrm{P}<0.001)$. Furthermore these factors tended to increase in women and decrease in men with advancing years. Such trends were small and variations in factor assays were considerable (coefficients of variation: factor XII $49 \%$, factor XI $29 \%$, antithrombin III, $22 \%$ ) and only the fall in factor XI in males and the increase in factor XI in females (comparing the 66-76 years and 20-40 years subgroups) attained statistical significance $(P<0.02$, $P<0.025$ ).

Factors X, VII, and V tended to increase in both sexes with increasing age although there was a slight decline in levels in males over 76 years compared with those aged 66-75 years. The rise in factor $X$ in women aged 66-75 years over those aged $20-40$ years was significant $(P<0.02)$ as were similar increases in factor VII levels in the elderly male and female subgroups (males: $P<0.05, P<0.05$; females: $P<0.01, P<0.005)$. Factor $V$ levels were higher in both groups of elderly females when compared with findings in young females $(P<0.025 ; P<0.01)$ whereas males over 76 years had significantly lower factor V levels than women of similar age $(P<0.01)$.

Factor VIII levels and platelet counts showed no age or sex trend in this series.

\section{OBESITY AND COAGULATION FACTORS}

Little influence of obesity upon coagulation factors was found in the elderly population studied here (table II) although the narrow range of skinfold thickness found in subjects may have obscured any real but small change attributable to obesity. Nevertheless factor VIII levels and obesity showed a significant inverse association $(\mathrm{r}=-0.55, \mathrm{P}<0.005)$.

\begin{tabular}{lcc}
\hline & $\begin{array}{l}\text { Males } \\
(n=26)\end{array}$ & $\begin{array}{l}\text { Females } \\
(n=30)\end{array}$ \\
\hline XII & -0.17 & 0.26 \\
XI & -0.09 & 0.28 \\
X & 0.32 & 0.22 \\
VII & 0.12 & 0.19 \\
V & -0.18 & -0.18 \\
VIII & -0.55 & 0.15 \\
Platelets & 0.29 & -0.17
\end{tabular}

Table II Correlation coefficients of skin thickness and factor levels in number of subjects (n) over 65 years

\section{Discussion}

Studies of biological changes associated with aging are difficult to interpret. There are considerable problems in defining 'normal health' in an elderly

\begin{tabular}{|c|c|c|c|c|c|c|}
\hline \multirow[t]{3}{*}{ Index } & \multicolumn{6}{|l|}{ Age Group } \\
\hline & \multicolumn{2}{|c|}{ 20-40 Years } & \multicolumn{2}{|c|}{ 65-75 Years } & \multicolumn{2}{|c|}{ Over 75 Years } \\
\hline & Male & Female & Male & Female & Male & Female \\
\hline $\begin{array}{l}\text { Number } \\
\text { Age (years) } \\
\left.\text { Platelets ( } \quad 10^{\%} / 1\right) \\
\text { Factor XII } \\
\text { Factor XI } \\
\text { Factor VIII } \\
\text { Factor X } \\
\text { Factor VII } \\
\text { Factor V } \\
\text { Antithrombin III }\end{array}$ & $\begin{array}{l}10 \\
30 \pm 2 \\
231 \pm 8 \\
136 \pm 19 \\
109 \pm 10 \\
109 \pm 10 \\
105 \pm 7 \\
84 \pm 5 \\
118 \pm 9 \\
114 \pm 5\end{array}$ & $\begin{array}{c}10 \\
30 \pm 2 \\
249 \pm 19 \\
127 \pm 21 \\
85 \pm 6 \\
118 \pm 9 \\
97 \pm 4 \\
92 \pm 6 \\
109 \pm 5 \\
106 \pm 8\end{array}$ & $\begin{array}{c}18 \\
71 \pm 1 \\
221 \pm 15 \\
128 \pm 15 \\
83 \pm 5^{3} \\
100 \pm 7 \\
119 \pm 5 \\
117 \pm 7^{4} \\
132 \pm 9^{2} \\
105 \pm 4\end{array}$ & $\begin{array}{c}10 \\
71 \pm 1 \\
222 \pm 25 \\
202 \pm 29^{1} \\
120 \pm 13^{4} \\
101 \% 10 \\
113 \pm 4^{+} \\
118 \pm 6^{4} \\
135 \pm 9 \\
133 \pm 11^{2}\end{array}$ & $\begin{array}{r}11 \\
81 \pm 1 \\
227 \pm 25 \\
103 \pm 14 \\
92 \pm 8 \\
104 \pm 10 \\
105 \pm 6 \\
104 \pm 8^{+} \\
115 \pm 9 \\
97 \pm 6\end{array}$ & $\begin{array}{l}22 \\
81 \pm 1 \\
220 \pm 12 \\
189 \pm 23^{1} \\
101 \pm 6 \\
104 \pm 8 \\
114 \pm 6 \\
121 \pm 5^{4} \\
94 \pm 7^{1.4} \\
121 \pm 5^{2}\end{array}$ \\
\hline
\end{tabular}

Table I The mean and standard errors of coagulation factors in the different age and sex subgroups

${ }^{1}$ Difference in means with respect to sex is significant for that age subgroup $(P>0.05)$

$2 \mathbf{P}>0.001$

3,4Difference in means with respect to mean of $20-40$ year age group attains significance $(P>0.05)(P>0.01)$ 
population and longevity itself may reflect ill defined selective pressures which could obscure pathophysiological trends. Nevertheless the present findings provide some insight into age-related effects upon the coagulation system.

The most consistent findings were increased levels of factors XII, XI, and antithrombin III in elderly females over males and a rise in factors XII, XI, X, VII, V, and antithrombin III in women aged 66-75 years compared with levels in younger women, with a subsequent decline in these factors in extreme old age. Changes in men were more variable with a rise and fall apparent in factors X, VII, and V while factors XII, XI, and antithrombin decreased slightly with increasing age.

Most previous studies of the effect of aging on the blood coagulation system have either not reported individual factor concentrations (Nilsson, 1964) or have not investigated such elderly populations as studied here (Korsan-Bengtsen, Bengtsson, and Tibblin, 1973). Fagerhol and Abildgaard (1970) described a gradual decline in antithrombin III levels in men from age 18-66 years and an age-related increase in postmenopausal women. Our findings suggest that such changes continue into old age. There has also been controversy as to the effects of sex and advancing years on factor VIII concentrations (Pitney and Arnold, 1959; Cooperberg and Teitelbaum, 1960; Pitney, Kirk, Arnold, and Stenhouse, 1962; Preston and Barr, 1964; KorsanBengtsen et al, 1973). In the small numbers studied here no significant differences in factor VIII levels were found amongst the different groups examined. However, a previously unreported association between factor VIII levels and leanness is described in elderly males. In a previous study of these volunteers we described a similar negative correlation between obesity and fibrinolytic activity in males (Hamilton, Dawson, Ogston, and Douglas, 1974). It appears that obesity is yet another situation where factor VIII concentrations and fibrinolytic activity are affected in the same direction.

While the biological significance of our findings is not readily apparent our results suggest that any study of the coagulation study must consider age- related changes and provide standards against which subsequent work can be compared.

We are indebted to $\operatorname{Dr} \mathrm{A}$. Robertson and his partners of Kincorth, Aberdeen, for generous help, cooperation, and permission to approach and study some of their patients who kindly participated in this study.

\section{References}

Cooperberg, A. A., and Teitelbaum, J. (1960). The concentration of antihaemophilic globulin (AHG) related to age. Brit. $J$. Haemat., 6, 281-287.

Denson, K. W. E. (1972). Appendices. I. The preparation of general reagents and coagulation factors. II. Techniques. In Human Blood Coagulation, Haemostasis and Thrombosis, edited by R. Biggs, pp. 587-675. Blackwell, Oxford.

Edwards, D. A. W., Hammond, W. H., Healy, M. J. R., Tanner, J. M., and Whitehouse, R. H. (1959). Design and accuracy of calipers for measuring subcutaneous tissue thickness. Brit. $J$. Nutr., 9, 133-143.

Fagerhol, M. K., and Abildgaard, U. (1970). Immunological studies on human antithrombin.'III. Influence of age, sex and use of oral contraceptives on serum concentration. Scand.J. Haemat., $7,10-17$.

Hamilton, P. J., Dawson, A. A., Ogston, D., and Douglas, A. S. (1974). The effect of age on the fibrinolytic enzyme system. J. clin. Path., 27, 326-329.

Kakkar, V. V., Howe, C. T., Nicolaides, A. N., Renney, J. T. G., and Clarke, M. B. (1970). Deep vein thrombosis of the leg. Is there a 'high risk' group? Amer. J. Surg., 120, 527-530.

Korsan-Bengtsen, K., Bengtsson, C., and Tibblin, E. (1973). Blood coagulation, fibrinolysis and platelet function in women aged $38,46,50,54$, and 60 ; the study of women in Gotenburg, 1968-1969. Acta med. scand., 193, 543-546.

Mancini, G., Carbonara, A. O., and Heremans, J. F. (1965). Immunochemical quantitation of antigens by single radial immunos diffusion. Immunochemistry, 2, 235-254.

Morrell, M. T., and Dunnill, M. S. (1968). The post-mortem incidence of pulmonary embolism in a hospital population. Brit. J. Surg., $55,347-352$.

Nilsson, I. M. (1964). Blood coagulation studies in the aged. In Age with a Future: Proceedings of the VIth International Congress of Gerontology, edited by P. F. Hansen, pp. 629-639. Munksgaard, Copenhagen.

Oettle, A. G., and Spriggs, A. I. (1951). Platelet counting In Recent Advances in Clinical Pathology, edited by S. C. Dyke, 2nd ed., p. 406. Churchill, London.

Pitney, W. R., and Arnold, B. J. (1959). Plasma anti haemophilic factor (AHF) concentrations in families of patients with haemorrhagic states. Brit. J. Haemat., 5, 184-193.

Pitney, W. R., Kirk, R. L., Arnold, B. J., and Stenhouse, N. S. (1962), Plasma anti-haemophilic factor (Factor VIII) concentrations in normal families. Brit. J. Haemat., 8, 421-428.

Preston, A. E., and Barr, A. (1964). The plasma concentration of factor VIII in the normal population. II. The effects of age, sex and blood group. Brit. J. Haemat., 10, 238-245.

Vessey, M.P., and Doll, R. (1969). Investigation of relation between use of oral contraceptives and thromboembolic disease: a further report. Brit. med. J., 2, 651-657. 